\title{
Talking About the Cultivation Mechanism of the Minorities Counsellors' Occupational Mental Quality from the Developmental Perspective*
}

\author{
Bo $\mathrm{Wu}$ \\ Student Potential Development Center \\ Xi'an Peihua University \\ Xi'an, China 710100 \\ Faculty of Humanities and Social Sciences \\ City University of Macau \\ Macau, China
}

\author{
Wenjing Yao \\ Student Potential Development Center \\ Xi'an Peihua University \\ Xi'an, China 710100
}

\author{
Liang Cai \\ Student Potential Development Center \\ Xi'an Peihua University \\ Xi'an, China 710100
}

\begin{abstract}
In recent years, ethnic minority counselors have been introduced and set up in various colleges and universities. On the one hand, they can better serve ethnic minority students in colleges and universities, and on the other hand, they can better convey education and ideological and political ideas to ethnic minority students. Then the professional psychological quality of this group becomes a new proposition.It includes Vocational Psychological Quality Access Mechanism for Counselors, the Guarantee Mechanism of Vocational Psychological Quality, Operation mechanism, Maintenance mechanism, Evaluation mechanism that Cultivation Mechanism of the Minorities Counselors' Occupational Mental Quality from the Perspective of Developmental Perspective . This study puts forward the operation and maintenance mechanism of vocational psychological quality training of ethnic minority counselors from the perspective of "workshop" model and development.
\end{abstract}

Keywords-developmental perspective; minoritycounselors; vocational psychological quality; cultivation mechanism

\section{INTRODUCTION}

In recent years, ethnic minority counselors have been introduced and set up in various colleges and universities. On the one hand, they can better serve ethnic minority students in

*Fund: 1. The Shaanxi Provincial Higher Education Commission set up the first batch of Shaanxi Normal Higher School Counselor Studio - Mind Garden Studio (2018SXFGZS18);

2. The Excellent Projects and Research Subjects of College Counselors' work in 2018 in Shaanxi Province - A Study on the Cultivation Mechanism of Professional Psychological Quality of Private College Counselors from the Perspective of Development (2018FKT52);

3. Xi'an Peihua University School-level Key Projects - Research on the Influence of Female Characteristic Education on Female College Students Mental Health - Taking Xi'an Peihua University as an Example (PHSZ201801). colleges and universities, and on the other hand, they can better convey education and ideological and political ideas to ethnic minority students. Then the vocational psychological quality of this group becomes a new proposition. By combing the research papers on the vocational psychology of college counselors, it is found that the subjects of most research are college counselors' competency and burnout. But psychological concepts such as professional commitment, professional identity, psychological contract, and self-efficacy have also been introduced into the field of research on the professionalization of counselors; however, at present, most of them are in the stage of introducing concepts, and the countermeasures are relatively few. At the same time, although there are many researches on the vocational psychological structure of college counselors, there are few researches on the mechanism of counselors' vocational psychological quality. In recent years, in order to do a good job in the education, service and management of minority students, colleges and universities have been assigned a few minority counselors. However, in addition to providing material security for these minority counselors, they have little research on the mechanism of minority psychological counselors' vocational psychological quality. Therefore, this study has carried out some explorations. The vocational psychological quality of minority counselors is not only related to the whole process of higher education for minority students, but also to the foundation of the all-round education pattern associated with minority students, to the practical improvement of methods of improving the affinity and pertinence of minority students in their work, to the minority socialist builders and successors who are concentrating on the development of morality, intelligence, physique and aesthetics all-round development. We will focus on cultivating new people in the era of national 
rejuvenation and continue to open the new era of ideological and political work in the new era.

\section{THEORETICAL SIGNIFICANCE AND PRACTICAL} SigNifiCANCE OF THE CULTIVATION MECHANISM OF ETHNIC COUNSELORS' VOCATIONAL PSYCHOLOGICAL QUALITY FROM THE PERSPECTIVE OF DEVELOPMENT

Counselors are one of the backbones of college students' ideological and political education. At the same time, they are also the managers of students who work in the front line of colleges and universities. They are the organizers, implementers and instructors of the daily ideological and political education and management of college students and accompany students through all stages of college life. As a specific group in the education system of colleges and universities, college counselors are the direct communicators of thoughts. They are the most important people to the college students who have close interaction with them [1], because their psychological quality will not only affect the psychological education function of the nine vocational functioning, also affect the basic psychological quality and implementation effect of other eight functions, as well as they will affect the formation and improvement of college students' psychological quality under the synergy. Minority counselors who are responsible for ideological and political education, service and management of minority students are even more important. Therefore, the cultivation of vocational psychological quality of minority counselors is very important, not only related to their competence, but also their effectiveness in the implementation of education and the development of the vocational functioning of minority counselors. We all know that after the party's revolutionary line is determined, the key factor is still on the "people". The vocational psychological quality of minority counselors will influence not only the whole process of higher education for minority students, but also minority students. The foundation of the all-round education pattern is related to the practical improvement of the work affinity and targeted methods for minority students. It is related to the cultivation of minority socialist builders and successors who are fully developed in morality, intelligence, beauty and beauty. As a newcomer to the era of national rejuvenation, the results of the new situation of ideological and political work in colleges and universities in the era of innovation will not be broken.

Therefore, this study can not only explore a vocational psychological quality cultivation mechanism suitable for a few college counselors, but also provide a reference for other colleges and universities to develop a vocational psychological quality cultivation mechanism for college counselors from a developmental perspective.

\section{MAIN CONTENTS OF RESEARCH ON THE CULTIVATION MECHANISM OF MINORITY COUNSELORS' VOCATIONAL PSYCHOLOGICAL QUALITY FROM THE DEVELOPMENTAL PERSPECTIVE}

\section{A. Basic Concepts}

Firstly, the vocational psychological quality of college counselors refers to the comprehensive implementation of the spirit of the document Central Committee No. 16 Order, the Ministry of Education No. 24 Order, the "Vocational Ability Standards for counselors of Colleges and Universities (Interim)", and the "National Medium- and Long-Term Education Reform and Development Plan (2010-2020)", the Central Committee No. 31, "Implementation Outline for the Improvement of the Ideological and Political Work of Colleges and Universities" (2017), to enhance the "Ten" task and content of ideological and political work as the program of action, with the of the counselors' "Nine" vocational function, including the core personality, role awareness, role experience, role expectations and so on.

Secondly, the research on the vocational psychological quality of minority counselors is more focused on analyzing the characteristics of minority counselors, the characteristics of ideological and political work of minority students, the psychological development and coordinated development of minority counselors and students, focusing on the counselor's vocational psychological quality from developmental perspective. In terms of content, the vocational perspective of the developmental perspective counselor should not only have the "Ninth" vocational functions, but also focus on the academic counseling for students (excavating learning potential, improving various abilities), personality counseling (self-improvement, self-realization), interpersonal relationship counseling (enhancement of social adaptability), psychological quality counseling (learning psychological adjustment, managing one's own emotions, maintaining a healthy mentality) [2]. Therefore, the "vocational psychology of minority counselors from the developmental perspective" requires counselors to have developmental education and professional psychological concepts, to have excellent personality and psychological quality, and rich theoretical knowledge and strong practical skills [2].

Thirdly, the cultivation mechanism of professional psychological quality of minority college counselors is a comprehensive cultivation mechanism refers to the vocational psychological access mechanism, vocational psychological security mechanism, vocational operation and vocational psychological maintenance mechanism and evaluation mechanism based on the professional psychological quality requirements of minority counselors from the perspective of development.

\section{B. Basic Research Content}

From the developmental perspective, the research on the vocational psychological quality mechanism of minority counselors includes the counselor's vocational psychological quality access mechanism, the vocational psychological quality guarantee mechanism, the operation and maintenance mechanism, and the complete mechanism of the evaluation mechanism. The operation and maintenance mechanism are the focus and difficulty.

1) The Access Mechanism of Minority Counselors' Vocational Psychological Quality from the Developmental Perspective: From the perspective of development, the admission of professional psychological quality of counselors in minority colleges and universities should include 
educational and professional psychological concepts with a developmental perspective. Whether it has excellent personality psychological quality and personality foundation, mature personality level, excludes personality characteristics of paranoia, marginal and excessive depression, has positive psychological quality and vision, and identify with national policy and ideological and political direction of China, has the inner motivation to master the theoretical knowledge and practice of developmental perspectives, builds a vocational qualification certification system for counselors, standardizes the procedures for selecting and improves the selection method. In general, the key focus of the above is on the entrance.

2) The guarantee mechanism of the cultivation of vocational psychological quality of minority counselors from the developmental perspective: Many colleges and universities have gradually established a counselor's vocational psychological quality cultivation organization, which is used to improve the construction of the counselor's vocational psychological quality cultivation team, to increase the support funds for the counselor's vocational psychological quality cultivation [3]. However, it is particularly important to be able to set up a corresponding guarantee mechanism based on the situation. Minority counselors are "weak" regardless of the number of counselors and the ethnic composition of their units. Therefore, in order to maintain this kind of psychology, the safeguard mechanism is very important.

3) Operation and maintenance mechanism of vocational psychological quality cultivation of minority counselors from thedevelopmental perspective

a) The relationship between the operation and maintenance mechanism of the cultivation of vocational psychological quality of minority counselors from the perspective of workshop mode and developmental perspective:

- From a developmental perspective, the vocational psychological quality requirements of counselors required for minority ideological and political work, student services and student affairs

After years of development and research, there is a general consensus that the work of minority counselors should not be "only satisfied with the psychological adaptation of the educated", but should "maintain their own psychological quality and cope with vocational psychological stress and conflict aware and resolute job burnout, improve self-esteem, while optimizing the psychological quality of all educated people, and promoting the mental health of educated people under the cultivation of counselors' vocational psychology."

- The driving effects of the workshop model and the internal "self-maintenance"

Psychological research proves that the subjective psychological "self-maintenance" ability formed by individuals due to personal growth needs is the core driving force for promoting mental health [4]. Therefore, the self-maintenance drive needs to be activated in a certain situation, and this self- recovery ability also needs daily nourishment, so the workshop mode can provide this mode.

- The adjustment function of workshop mode and external support system

The group experience and supervision system in the workshop mode is an important part of the external support system, which directly affects the vocational psychological quality and vocational ability of the counselor.

b) Contents and assumptions of development of workshop model: With the aim of cultivating talents with ethics, we will build a team of counselors with an international perspective, a solid foundation of psychological theory, and a variety of "psychological workshops" that can innovate and carry out distinctive features.

The psychological workshop mode not only acts on the operation and maintenance mechanism of the vocational psychological quality cultivation of minority counselors, but also the form and approach of innovative ideological and political education. Psychological workshops correspond to workshop of psychology. Based on people with experience in a certain field or genre of psychology, small groups of 25-40 members are under the guidance of this person through activities, discussions and other forms to discuss a topic or conduct psychological growth motivation team training. Because of the small number of participants and the ease of interaction, participants have access to many growth experiences that are not available through regular lectures. The world's mainstream expression art mentality model has very different meanings from psychological activities. Usually, the form, interest and participation of psychological activities are more focused, and the time is mostly based on the short-term topic. However, in addition to the above characteristics, the psychological workshop mode tends to be more professional psychological workshop mode in time setting, such as closed group, once a week, one and a half hours each time, for 6 consecutive weeks, and so on. In the professional background, the psychological workshop model is more prominent in the combination of psychological theory and audience, such as the exploration of "self" subject; emotion and complex theory, psychological adaptation and personality development theory, psychological type and MBTI, etc., highlights the guidance of the psychological theory background for the workshop, highlights the development of group dynamics and the exploration of self in various workshops.

c) International vision and resources: Extensive study of mental health education in international and domestic universities. Based on maintaining the original characteristics, we will further study and innovate the model of the psychological workshop, focusing on the various forms of psychological counseling that counselors and students like to participate in and enjoy, such as active writing technical psychological workshops, gardening psychological workshops, wooden psychology workshops, baking psychology workshops, mandala (identity integration) painting psychological workshops, fairytale psychological drama psychological workshops, group sand table psychological workshops, pottery workshops, dance psychology workshops, 
hand-sewn psychological workshops, etc., and guide the counselors to develop their own goals such as self-exploration, self-awareness, and self-identity integration as the overall idea to realize the development of the counselor's potential.

d) Expand the "depth" of the counselor's vocational psychological quality cultivation, and make full use of worldclass resources: Enter IAAP (international association for analytical psychology) spiritual garden and ISST public welfare project supervision system and registration system to further study and cultivate systematic theories.

e) Carry out research on related topics and translation of international frontier academic literature

f) Forming a team with the vocational psychological quality cultivation of college counselors, and conducting selfhelp and mutual assistance service project guidance and workshop model copying and practice of counselors' vocational psychological quality: Through the cultivation of the workshop mode, a team of vocational psychological quality cultivation teams, self-help and mutual help teams with echelon and various characteristics are formed. Through the study and supervision of the vocational platforms of IAAP and ISST and China's registration system, we can cultivate a professional team with international vision, professional knowledge, innovative ideological and political education and mental education carriers and models.

\section{EVALUATION Mechanism}

\section{A. Making Clear Core Points}

The psychological quality cultivation mechanism of minority counselors is based on the construction of counselors and the promotion of ideological and political education in colleges and universities. It is also based on the personal development of counselors [5]. The core is to respect the individuality development of the counselors in line with professional needs, to focus on the form and diversity of the workshop while attaching importance to the overall construction [6], the international innovation activities mobilize the initiative of the counselors to participate actively, so as to truly realize the positive guiding role of the evaluation mechanism in the cultivation of counselors' psychological quality.

\section{B. Establishing Professional Evaluation Standards}

The establishment of professional evaluation standards is an important indicator of professional development. Establishing professional evaluation standards is conducive to ensuring the development direction of minority counselors, which is conducive to further standardizing counselors' psychological and professional behaviors and promoting the professional development of counselors [7].

\section{Supplementing and Establishing the Evaluation Rules for Minority Counselors}

There are few evaluation policies and regulations for counselors in China, and there is a lack of theoretical guidance and legal support for colleges and universities in the evaluation of counselors. On March 25, 2014, the Ministry of Education issued the "Vocational Ability Standards for counselors of Colleges and Universities (Interim)", which standardized and required the counselors vocational profile, basic requirements, and vocational level ability standards. The education administrative departments at all levels are required to regard the "Standards" as the basic basis for the construction of counselors in the region, and improve the management system for the appointment, evaluation and introduction of counselors [8]. The "Standard" does not propose a certain evaluation standard and evaluation system for psychological quality. Therefore, from the developmental perspective [9], combined with the characteristics of ethnic minorities, the development of evaluation mechanisms will help the counselors to grow their own and help the minority to follow the rules.

\section{CONCLUSION}

In short, paying attention to the psychological development of this group of minority counselors, and carrying out the practical psychological mechanism construction of minority counselors, not only cares for this group, provides psychological support, psychological development and growth mechanisms for minority counselors, but also lays a solid psychological foundation for them to further enrich themselves, challenge themselves and realize the value of life. A team of minority counselors who love college students' ideological and political education, have a strong sense of responsibility and mission of college students' ideological and political education, are willing to contribute, and develop their physical and mental health can support and build the psychological counseling and development of minority students, can further provide professional guidance from the psychological security and development to the ideological development of minority students; can also create a good educational environment for the learning, life and growth of minority students.

\section{REFERENCES}

[1] Zeng Xiaoyun. On the Cultivation of College Counselors' Vocational Psychological Quality[J]. Kaoshi Zhoukan, 2008-06-10 (in Chinese)

[2] Pi Binxia. Research on the professionalization of vocationalization of private college counselors [D]. Master's Thesis of Hunan University, 2014-10-20 (in Chinese)

[3] Vocational ability standards of college counselors (interim) - Internet Documentation Resources (http://www.worlduc.c). 2016/10/29 8:37:00 (in Chinese)

[4] Zhang Yanfen. Analysis of the vocational psychological maintenance system of college counselors. Journal of Yangzhou University (Higher Education Research Edition). 2016-12-07 1 (in Chinese)

[5] Sun Xinling. Philosophical thinking on the issue of psychological harmony [J]. Theoretical exploration, 2016(6) (in Chinese)

[6] Chen Yujiong. Stress analysis and mitigation methods of college counselor's job burnout [J]. Journal of Zhejiang University of Traditional Chinese Medicine, 2013. (in Chinese)

[7] Wang Guoliang. Analysis on the psychological pressure of college political counselors and its adjustment [J]. Journal of Socialist Guide, 2007 (in Chinese)

[8] He Jingliang. Analysis on the mental health problems of college counselors [J]. China Education Innovation Heral, 2015(13) (in Chinese)

[9] Weihe. Sociological Analysis of Educational Activities - A Study of Educational Sociology [M]. Educational Science Press, 2001, 4. (in Chinese) 